Kestenbaum is well known for his work on nystagmus, and as would be expected, his chapter on this difficult subject is full of useful information which is conveniently summarised in tabular form.

Disturbances of -ocular movements are also very fully gone into, under the headings of Eye muscle palsy, Gaze movement and Gaze palsy. Various methods are described, but no mention is made of the Hess Screen, possibly because the author is not satisfied with it.

In dealing with the pathology of the optic nerve, the author has much valuble information to give, but he does not mention the absence of papilloedema in purely pontine growths, and the frequent association of a sub-tentorial tumour with the presence of a macular fan.

The characteristics of " neuro-ophthalmologic examination" appear to be :- clarity of expression; simplicity of technique for tests, and the incorporation of much information of practical value which is not obtainable elsewhere. The practical nature of much of the text makes this book a difficult one to review, particularly by armchair reading. One has the feeling all the time that it should be taken into the Clinic, where a far better appraisal of its value could be made by using it as an aid to the investigation of patients.

Dr. Kestenbaum is to be congratulated on having produced a volume of outstanding value.

\title{
CORRESPONDENCE
}

\section{CONJUNCTIVITIS IN EXPOSURE TO DIMETHYL-SULPHATE}

To the Editors of THE BRITISH JOURNAL OF OPHTHALMOLOGY.

DEAR SIRS, - In your latest issue of June (p.373), H. J. Stern describes a case of conjunctivitis due to exposure to vapours of dimethyl-sulphate (abbrev. D.M.S.). He also cites papers of Weber and of different authors, all published early this century. With respect to the rarity of poisoning with D.M.S., it would be of interest to recollect the cases seen at Budapest in 1934. At one of our chemical works, a $1.5 \mathrm{lb}$. glass container filled with D.M.S. was broken by a labourer. One out of the three injured came under care of J. Petres, the other two were seen by the laryngologist G. Boskowitz and myself. (Case record in the Rep. on the 4th General Meeting of Hungarian Physicians 1934). The most severe injuries which ended fatally under symptoms of lung-oedema on the fourth day occurred in the girl who had caused the accident. Thirteen hours 
after the injury, tracheotomy had to be performed on account of sudden onset of glottis-oedema; this was followed by a membranous laryngo-tracheo-bronchitis. This massive poisoning resembles that with chlorine, the action of both substances having much in common. With the other patients, there was only some irritation of the respiratory tract. Eye symptoms set in at the very moment of contact with the fumes in all three cases and corresponded to those described by Stern, except that the cornea showed multiple punctate erosions and in the superficial layers round-shaped faint infiltrations which have proved most resistant to therapeutic procedures. A remarkable symptom consisted in corneal hypaesthesia, D.M.S. being a so-called anaestheticum dolorosum. Several weeks passed before the eyes recovered. For first aid we performed lavation with freshly prepared sodium bicarbonate solution. Later, alkaline ointment which had been used against gas-injuries during the first World War, was applied. (Rp. natr. borac. 0,1, natr. bicarb. 0,2, adip Lanae, aqu. dist. aa. 1,0 , vasel. flav. 8,0 .)

Yours faithfully,

CORNELIUS RAÁB, M.D.

Budapest, V. Gezau. 3.

June 25, 1947

To the Editors of THE BRitish Journal of Ophthalmology.

Dear Sirs. - In one of your last issues (June) Mr. H. J. Stern gave an account of eye-injury due to dimethyl-sulphate fumes. May I call your attention to my paper published in the Amer. $J l$. of Ophthal. (Vol. XX, No. 7, 1937) where the question is fully reviewed. The typical ocular findings are following latency (hydrolysis), corneal lesion varying from mild roughening to extensive erosion, accompanied by photophobia, lacrimation, etc. For treatment I recommend alkaline cream, as possibly the local changes are due to sulphuric acid. On the other hand, methyl alcohol, the other splitproduct may cause similar erosions on the cornea. Cocaine seems to be contraindicated owing to its undesirable effect on epithelium. Irritating atmosphere should be avoided in after-care. Homatropine is of benefit against sphincter spasm.

I am, Sir,

Yours very sincerely;

STEPHEN DE GRósz, M.D.

Budapest, Hungary.

Associate-Professor, Eye-Hospital, University Medical School. Budapest. 